Olgun, S., Yilmaz, M., Clarke, P. M., \& O’Connor, R. V. (2017). A Systematic Investigation into the Use of Game Elements in the Context of Software Business Landscapes: A Systematic Literature Review. In A. Mas, A. Mesquida, R. V. O'Connor, T. Rout, \& A. Dorling (Eds.), Software Process Improvement and Capability Determination: 17th International Conference, SPICE 2017, Palma de Mallorca, Spain, October 4-5, 2017, Proceedings (pp. 384-398). Cham: Springer International Publishing. https://doi.org/10.1007/978-3-319-67383-7_28

\title{
A systematic investigation into the use of game elements in the context of software business landscapes: A Systematic Literature Review
}

\author{
Serhan Olgun ${ }^{1,2}$, Murat Yilmaz ${ }^{1,2}$, Paul Clarke ${ }^{3,4}$, Rory V. O’Connor ${ }^{3,4}$ \\ ${ }^{1}$ Çankaya University, Department of Computer Engineering, Turkey \\ ${ }^{2}$ Virtual Reality Research Laboratory, Çankaya University, , Turkey \\ c1271202@student.cankaya.edu.tr,myilmaz@cankaya.edu.tr \\ ${ }^{3}$ School of Computing, Dublin City University, Ireland \\ ${ }^{4}$ Lero - the Irish Software Research Centre \\ \{paul.m.clarke, rory.oconnor\}@dcu.ie,
}

\begin{abstract}
The software development process is a set of activities to produce software applications that human plays a crucial role. Since it is a people centric activity some obstacles (i.e. user motivation, engagement, communication and collaboration) may occur. Therefore, software business organizations are seeking new productive solutions, try different tools and methods in order to overcome the challenges and improve their software business processes. A lot of researches have been made to increase the quality and enhance the software development process. Along with these innovative research new efficient techniques and concepts offered. As a solution the term gamification or using game elements in non-game contexts have been realized to enhance the software development process and overcome the challenges related to human factors. However, the applicability of the use of game elements in the context of software business landscapes is still controversial issue and not totally proved yet. Many researches and empirical studies have been conducted for the benefits of it and how these game elements affect the quality of software development process. Thus, in this paper a systematic literature review was conducted in order to investigate the application of game elements both in research and industrial levels of software development and as well as in software business landscapes for further research.
\end{abstract}

Keywords: gamification, software development, game elements, systematic mapping, literature review, systematic review 


\section{Introduction}

Software development organizations are professional business firms, which are founded so as to develop high quality software products that satisfy the customer expectations and their business objectives. In these organizations valuable robust and reliable software products are produced as a result of attentive development process by the experienced development teams. A software product development requires an extensive development process, which includes analysis, development, testing and maintenance steps. Yilmaz states that $[1$, pp. 18] "A software development process is considered as the coordination of structural social activities (e.g. management, production and maintenance) coupled and constrained with a set of individuals' (i.e. participants who perform the activities) roles and skills for producing software artifacts in a predefined productivity level". Theoretically, software development process is an organized structure that has consecutive steps to produce software applications. This process is performed by small, medium or large-scaled experienced software development teams by communicating with their customers in software business companies. In other words, this process is a team work that requires quite effective people involvement, engagement, collaboration and motivation to accomplish the process steps, so it concerns both software developers and customers.

Since it is a human centric activity, in the course of proceedings some obstacles may occur to achieve the goals. Human factors (i.e. user motivation, engagement, communication and collaboration) are major parameters for the success of the development process. This can be clarified by the effects of human role in the development process by being a stakeholder (influencing the process by being a customer, developer and manager separately) related to the software product. Reasons for why these problems occurred while producing complex software products are: lack of communication among team members that causes collaboration problems, misunderstood of business requirements and objectives from customer, late performance evaluation and lack of reward systems by the management and also insufficient technical experiences [20].

With respect to the state of the art as described the idea is to use game elements to engage, motivate, train and monitor all the employees [21] to make them passionate to involve them in the whole development process in the context of software business landscapes. The gamification broadens a new horizon almost all areas in the nongame contexts. Its description has been made with the following statement: "gamification is defined as the use of game design elements in non-game contexts." [4]. In gamified contexts a rewarding mechanism exists to encourage people and excite people's attention to increase the engagement. If gamification applied to the software development it may several advantages. From employee perspective, because of its rewarding mechanism to increase engagement, knowledge, motivation and collaboration issues. From managers' perspective, it may also have advantages for the performance management to monitor the development team members. 
The application of game elements in the context of software business landscapes is still not an obvious issue and needs research and experiments on it. Therefore, this study investigates the applicability of the use of game elements in the context of software business landscapes and how these game elements affects the quality of software development in software business landscapes in order to overcome the challenges in the software industry.

The purpose of this research is to investigate the use of game elements in the context of software business landscapes. To summarize, this paper aims to address the following research questions:

i). What is currently known about people's motivation, engagement and performance issues of software development process?

ii). Which approaches can be applied into software business landscapes to increase the quality and performance of software development?

iii). What are the examples of these approaches for the software industry?

iv). How these approaches affect the quality of software development in software business context?

The paper is structured as follows: Section 2 presents the research methodology about how the systematic literature review was planned. Section 3 presents the analysis and results that is obtained from the study. Section 4 discusses the future work and concludes the paper.

\section{Background}

In this section background information about the related topics will be presented. In first, we provide brief information about gamification.

\subsection{Gamification}

The term gamification is defined in [4] as "using game design elements in non-game contexts to motivate and increase user activity and retention". As it is clearly stated in its definition gamification uses game design elements in gamified environments to change people's behavior in positive manner and keep engaged and motivated them in particular tasks in non-digital environments such as workplaces, schools or software applications. By the increase in the application of real life examples of gamification in different domains the popularity and usage of it has been growth in the last years. One of the domains where gamification is used is education and training [7] to increase the motivation, engagement and performance of students. Gamification has also been used to maximize the user engagement and keep user motivated by entrepreneurs, customer oriented web site owners [8]. StackOverflow [9] is as an example where the game elements are intensely used. This web site is a question and answer based web site for developers where users take badges or performance rates according to their activities in particular actions. Because of its effectiveness and efficiency, it has also 
been applied in corporate environments to make better employee's performance while they accomplish their tasks and works [10].

\subsection{Gamification and Software Development Process}

This study focuses on the applicability of the gamification in software business landscapes and how these game elements affect the quality of software development process in software business landscapes in order to overcome the challenges in the software industry. Thus, this makes gamification a promising field to overcome the challenges related to human factors such as people involvement, engagement, collaboration and motivation throughout software development process. Due to the above stated reasons, some software development process tools have started to integrate to game elements to benefit from gamification principles. JIRA Hero [11], RedCritter [12], PropsToYou [13], ScrumKnowsy [14], MasterBranch [15] or Visual Studio Achievements [16] are the examples of commercial tools that are gamification mechanisms adopted in the context of software business landscapes. Therefore, researchers and practitioners recognized that the game elements can be applied to the software business landscapes. However, the applicability of this issue is not obvious so it needs some research on it. Thus, a lot of proposals and academic researches about the topic have been published. Therefore, in this paper, a research approach is proposed for understanding all following effects to improve the quality of a software development process by conducting a systematic literature review.

\section{Research Methodology}

The Systematic Literature Review (SLR) research methodology is used to conduct this survey. A systematic literature review is a research type to find out what we know and what we do not know based on the focused research questions. "As a research area matures there is often a sharp increase in the number of reports and results made available, and it becomes important to summarize and provide overview." [2] Therefore, systematic literature reviews should clearly include the question that it attempts to answer and report fully on the methods that have been used. According to Kitchenham, "Systematic Literature Review (SLR) is a means of identifying, evaluating and interpreting all available research relevant to a particular research question, or topic area, or phenomenon of interest." [3] As described, the word systematic stands for planned, methodical acting and review stands for critical appraisal of works.

Systematic $\rightarrow$ Planned, methodical acting.

Review $\rightarrow$ Critical Appraisal of Works.

Synthesis $\rightarrow$ Get together findings. 
This planned and methodical literature review is conducted by carrying out these steps. The Figure 1 shows the Systematic Literature Review process and steps. These steps are briefly explained below:

- Planning: It is the first step of the review where the need for review is identified, research questions are defined, and a review protocol is developed and evaluated.

- Conducting: It is the second step of the review which includes the following sub steps: Primary study selection, the data extraction, study quality assessment, and the data synthesis where the obtained data are synthesized.

- Documenting: It is the last step of the review to report the dissemination of information by drawing a conclusion and considering threats.

Hence, the systematic literature review is used to review the primary studies to find out the answers about the research questions and observe the results. As Petersen [2] states SLR uses existing studies related to research topic describes the context and summarize the results. Kitchenham [6] explains the reasons why systematic literature review is conducted:

- "To summarize the existing evidence concerning a treatment or technology e.g. to summarize the empirical evidence of the benefits and limitations of a specific agile method.

- To identify any gaps in current research in order to suggest areas for further investigation.

- To provide a framework/background in order to appropriately position new research activities."

By this systematic literature review the existing proposals and research works for applying game elements into software development process in software business landscapes are determined, analyzed and classified to attempt to answer the questions and report them clearly for future research. While conducting this review, recommendations in $[3,17]$ is followed to make the review better and decide the best solution for the investigation.

This section continues with describing search strategy and definition of research questions, identification of inclusion and exclusion criteria, searching relevant studies, extracting data and, at the end, synthesis of the study. 


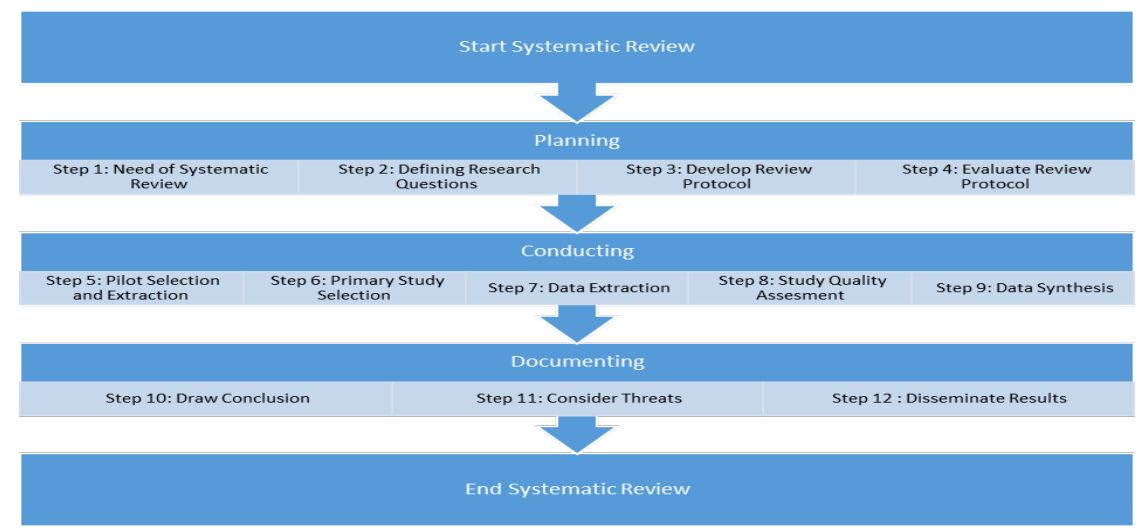

Fig. 1: Systematic Literature Review Steps (Adapted from [6])

\subsection{Research Questions, Data Sources and Search Strategy}

Depending on the systematic literature review principles [3], in this step, some research questions are established for this study to find answers from existing research work and proposals related to application of game elements to software development process in the context of software business landscapes. Research questions are related to applicability of the use of game elements in the context of software business landscapes and how these game elements affect the quality of software development in software business landscapes in order to overcome the challenges in the software industry. Different perspectives for applying game elements into software business landscapes are considered and associated with each research question separately. The research questions and their aims for this systematic review are described in Table 1.

Table 1. Research Questions for the Systematic Review

\begin{tabular}{|c|c|c|}
\hline ID & Question & Aim \\
\hline RQ1 & $\begin{array}{l}\text { What is currently } \\
\text { known about people's } \\
\text { motivation, engagement } \\
\text { and performance issues of } \\
\text { software development } \\
\text { process? }\end{array}$ & $\begin{array}{l}\text { To identify which factors } \\
\text { affects the people's motivation } \\
\text { and performance during the } \\
\text { software development process. }\end{array}$ \\
\hline RQ2 & $\begin{array}{l}\text { Which game elements } \\
\text { and gamification } \\
\text { approaches can be applied } \\
\text { into software business } \\
\text { landscapes to increase the } \\
\text { quality and performance of } \\
\text { software development? }\end{array}$ & $\begin{array}{l}\text { To determine which game } \\
\text { elements and gamification } \\
\text { approaches can be applied to } \\
\text { software business landscapes to } \\
\text { enhance the success stories. }\end{array}$ \\
\hline RQ3 & What are the examples & applied \\
\hline
\end{tabular}




\begin{tabular}{|l|l|l|}
\hline & $\begin{array}{l}\text { of these approaches for the } \\
\text { software industry? }\end{array}$ & $\begin{array}{l}\text { approaches in the software } \\
\text { industry. }\end{array}$ \\
\hline RQ4 & $\begin{array}{l}\text { How these approaches } \\
\text { affect the quality of } \\
\text { software development in } \\
\text { software business context? }\end{array}$ & $\begin{array}{l}\text { To determine which } \\
\text { approaches remedy the software } \\
\text { quality. }\end{array}$ \\
\hline
\end{tabular}

These research questions are going to be guide for the data extraction phase and it helps to avoid reading full text of current research works related to the review. By the help of the research question that are stated above we focused on how game elements and mechanics remedy to increase the quality of software development process. During this review we reviewed the current research works and inspected how they focus on the gamification and software development process. Moreover, we observed other papers' proposals and approaches to find the efficient and effective solutions. For example, Research Question 1 (RQ1) focuses on investigation of identification for which factors affects the people's motivation and performance during the software development while Research Question 2 (RQ2) focuses on which game elements and gamification approaches or game elements such as badges, points award mechanisms can be applied to software business landscapes to enhance the success stories and increase the motivation of the people of the software development process. In Research Question 3 (RQ3) we identified the real life examples that adopts the gamification technique to their software development process. And finally, in Research Question 4 (RQ4) we observed how these approaches affect the quality of software development process in the industry.

To get a clear picture of current research work and find the answers to research questions, popular and reliable data sources are used to carry out this review. The search strategy included the academic electronic databases and Google Search is used for including extra publications and contributions for this study. The following academic electronic databases are used in this review:

- Çankaya University Electronic Database

- IEEE Explore

- Science Direct

- Access Engineering

To find the answers to conduct this review using the electronic data sources some special combinations, keywords and search strings are designed. To design the search strings, the following keywords are used as major terms: Software Development Process and Game Elements and Systematic Review. This search string is designed according to steps which are stated in [19] and all these terms related to this review topic is combined using Boolean AND or OR operator to retrieve the articles that are only related to this topic.

The search string that is used in this review study is indicated in Table 2 
Table 2. Search strings for this Systematic Literature Review

\begin{tabular}{|c|c|}
\hline Major Terms & Alternative Terms \\
\hline $\begin{array}{l}\text { Software Development } \\
\text { Process }\end{array}$ & $\begin{array}{l}\text { ((software development) OR } \\
\text { (software engineering) OR } \\
\text { (software process) OR } \\
\text { (software development phases) OR } \\
\text { (software development lifecycle) OR } \\
\text { (software planning) OR } \\
\text { (software testing) OR } \\
\text { (software analysis) OR } \\
\text { (software maintenance) OR } \\
\text { (software design) OR } \\
\text { (software quality) OR } \\
\text { (software configuration management) OR } \\
\text { (software validation) OR } \\
\text { (software verification)) AND }\end{array}$ \\
\hline Game Elements & $\begin{array}{l}\text { ((gamification) OR } \\
\text { (gamifying) OR } \\
\text { (gamify) OR } \\
\text { (gamification mechanisms) OR } \\
\text { (game mechanics)) }\end{array}$ \\
\hline
\end{tabular}

These keywords and search strings are built up based on the research questions to get as many papers possible. Also, the alternative keywords and terms are added to major terms (shown in Table 2) to retrieve and cover more papers from the stated electronic databases. These search strings are applied to title, abstract and keywords to get the results. The Table 3 is presented to summarize the search strategy which is described above.

Table 3. Search Strategy for this study.

\begin{tabular}{|c|c|c|}
\hline \multirow[t]{2}{*}{ Data Source } & Academic Search: & $\begin{array}{ll}\text { - } & \text { Çankaya University } \\
& \text { Electronic Database } \\
\text { - } & \text { IEEE Explore } \\
\text { - } & \text { Science Direct } \\
\text { - } & \text { Access Engineering }\end{array}$ \\
\hline & Non - Academic Search & - Google Search Engine \\
\hline
\end{tabular}




\begin{tabular}{|c|c|}
\hline Items & $\begin{array}{ll}\text { - } & \text { Academic Papers } \\
\text { - } & \text { Academic Publications } \\
\text { - } & \text { Journals } \\
\text { - } & \text { Book Sections } \\
\text { - } & \text { Conference Papers } \\
\text { - } & \text { Online academic } \\
& \text { publications } \\
\end{array}$ \\
\hline Search Applied to & $\begin{array}{l}\text { Title ,abstract, } \\
\text { Keywords }\end{array}$ \\
\hline Language & - Only written in English \\
\hline Publication between & - $2010-2017$ \\
\hline
\end{tabular}

\subsection{Study Selection Criteria}

Study selection criteria describe the inclusion and exclusion standards whether to include or not the existing research works and proposals depending on the research questions, search string and strategy when conducting a systematic literature review. Therefore, a search result must meet the constraints that are defined in inclusion and exclusion standards. Thus, the inclusion standards include the search result whereas the exclusion standards eliminate the search result in the review.

The inclusion and exclusion criterion need to be defined to increase to more reliable results and decrease the risk to stray away from the topic. In other words, study selection criteria are designed and used for processioning for the review. Thus, this enables other researchers to rework by carrying out review using the same standards. When defining the study selection standards some criterion should be followed. The inclusion criteria should not be too general or too strict. When it is too general, the poor quality studies may be included and it affects the final results. On the other hand, when it is too strict, the entire related studies might not be presented in the final result. For this study, the inclusion standards are defined to get clear and reliable results. Studies are eligible for inclusion in the review if they presented empirical data on software development that are used game elements in their business context. Therefore, only academic papers and publications, professional forums and contributions such as conferences, online publications and book sections which related to this review domain are included to inclusion standards. Moreover, publications between 2010 and 2017 and only written in English is considered as the part of inclusion standards. On the other hand, according to search results from search strings, the search results including irrelevant data are excluded for this systematic review. Also, non - academic results, people opinions, personal blogs and personal web pages from the search results are excluded for this study. The review also excluded the academic results that meet the following criterion: duplicate papers that are retrieved from different databases, the papers available with only its abstracts, papers related to gamification of other domains (education, health, etc.)

The Table 4 presents the study selection criteria that is used in the review. 
Table 4. Study Selection Criteria

\begin{tabular}{|c|c|}
\hline Inclusion Criteria & $\begin{array}{l}\text { - } \text { Results including the relevant data } \\
\text { - } \text { Academic Papers } \\
\text { - } \text { Academic Publications } \\
\text { - } \quad \text { Book Sections } \\
\text { - } \quad \text { Conference Papers } \\
\text { - } \quad \text { Online academic publications } \\
\text { - } \quad \text { Papers written in English } \\
\text { - } \quad \text { Publications between } 2010 \text { and } 2017 .\end{array}$ \\
\hline Exclusion Criteria & $\begin{array}{l}\text { - Main focus is not related gamification of } \\
\text { - } \quad \text { Poftware development process } \\
\text { - } \quad \text { Duplicate papers retrieved from different } \\
\text { databases. } \\
\text { - Non - academic publications } \\
\text { - Magazines, Personal web pages and blogs, } \\
\text { Personal opinions. }\end{array}$ \\
\hline $\begin{array}{l}\text { Exclusion Criteria } \\
\text { for full text }\end{array}$ & $\begin{array}{l}\text { - Papers related to gamification of other } \\
\text { domains (education, health, etc.)s } \\
\text { - Papers included the summary of conference } \\
\text { notes. }\end{array}$ \\
\hline
\end{tabular}

\section{Results}

We made our research using systematic literature review methodology by following the recommendations that are explained in [3, 17]. In first we developed search strings, identified data sources and decided study selection criteria, which are described in detail in Section 3. At the end, by following this search strategies we accessed and examined a lot of research work extracted the irrelevant data related to topic and collect the results to address the research questions. Table 5 shows the search results of each steps of the review process. As a result, number of 10 primary studies were obtained and these primary studies are listed in Appendix A section.

Table 5 The results obtained

\begin{tabular}{|c|c|c|}
\hline Step & Process & $\begin{array}{c}\text { Number of } \\
\text { Papers }\end{array}$ \\
\hline
\end{tabular}




\begin{tabular}{|c|l|c|}
\hline Step 1 & \multicolumn{1}{|c|}{ Search, data obtain } & 1093 \\
\hline Step 2 & $\begin{array}{l}\text { Data extraction, reading } \\
\text { keywords, title or abstract parts }\end{array}$ & 64 \\
\hline Step 3 & Reading full text paper & 33 \\
\hline
\end{tabular}

\subsection{Research Questions}

In this section we made an analysis to answer the research questions using the data that we obtain while conducting this review.

\begin{tabular}{|c|c|}
\hline Research Question & Result \\
\hline $\begin{array}{l}\text { Research Question } 1 \text { (RQ1): } \\
\text { What is currently known } \\
\text { about people's motivation, } \\
\text { engagement and } \\
\text { performance issues of } \\
\text { software development } \\
\text { process? }\end{array}$ & $\begin{array}{l}\text { User involvement plays a crucial role in } \\
\text { software development process Therefore; lack } \\
\text { of user involvement affects the software } \\
\text { development process in negative manner. } \\
\text { Efficient and effective user involvement and } \\
\text { user engagement requires high motivational } \\
\text { aspects to increase the performance issues } \\
\text { related to human factors. [A3] and [A4] } \\
\text { proposed that using game elements and } \\
\text { mechanics increases the user involvement by } \\
\text { increasing the user motivation, engagement } \\
\text { and collaboration issues. As the performance } \\
\text { issues considered in software development an } \\
\text { explicit analysis is the key factor. Therefore, } \\
\text { in their proposals in [A4] collaborative } \\
\text { environment with team members and also } \\
\text { stakeholders are important for better } \\
\text { understanding to produce a well-understood } \\
\text { software product. To build a collaborative } \\
\text { environment they propose to game elements } \\
\text { such as ranking systems and badges. In [A3] } \\
\text { to increase the people motivation and } \\
\text { engagement their proposal is award and point } \\
\text { mechanism. }\end{array}$ \\
\hline $\begin{array}{l}\text { Research Question } 2(\mathrm{RQ} 2) \text { : } \\
\text { Which game elements and } \\
\text { gamification approaches can } \\
\text { be applied into software } \\
\text { business landscapes to } \\
\text { increase the quality and } \\
\text { performance of software }\end{array}$ & $\begin{array}{l}\text { We use this research question to determine } \\
\text { which game elements and gamification } \\
\text { approaches can be applied to the software } \\
\text { development process in software business } \\
\text { landscapes to enhance the success stories. We } \\
\text { classify and examine the primary studies that } \\
\text { are about using game elements and mechanics. }\end{array}$ \\
\hline
\end{tabular}




\begin{tabular}{|c|c|}
\hline development? & $\begin{array}{l}\text { According to this analysis }[5,23,24] \text { that we } \\
\text { made we identify the following game elements } \\
\text { and mechanics that may be applied into the } \\
\text { software business landscapes to increase the } \\
\text { quality and performance of software } \\
\text { development. } \\
\text { - Rankings } \\
\text { - Badges } \\
\text { - Levels } \\
\text { - Quests } \\
\text { - Awards }\end{array}$ \\
\hline $\begin{array}{l}\text { Research Question } 3 \text { (RQ3): } \\
\text { What are the examples of } \\
\text { these approaches for the } \\
\text { software industry? }\end{array}$ & $\begin{array}{l}\text { We choose this research question to show and } \\
\text { exemplify the applied approaches in the } \\
\text { software industry. In this research question we } \\
\text { focused on the real life examples that } \\
\text { gamification elements used. We observed that } \\
\text { some glorious version tools and source } \\
\text { controls in the industry such as JIRA [11] } \\
\text { RedCitter [12] Visual Studio Achievements } \\
\text { [16] basic game elements such as badges, } \\
\text { levels and awards. In these version controls, } \\
\text { the performance of each team members can be } \\
\text { monitored and decided which team member is } \\
\text { more productive compared to the others. By } \\
\text { this way more productive team member is } \\
\text { rewarded. Januszevski in [A1] indicates that } \\
\text { the use of gamification elements the Visual } \\
\text { Studio platform to increase motivation and } \\
\text { performance of the team members. }\end{array}$ \\
\hline
\end{tabular}

\section{Conclusion}

In this paper we conducted a systematic literature review to classify and characterize the state of the art as regarding applying game elements into software development process into software business landscapes. In first we made a deep literature research by using the search strings that we developed at the beginning of the literature review to address each research questions to reach the goal. After we accessed data sources to show the applicability of gamification into software development process we performed a data inclusion and exclusion process to reach the goal. After this process we classified our primary studies according to their properties which are their process areas, type of game elements and mechanics that are applied in their proposals and how their effects. Moreover, we analyzed the experimental evidences of real life examples to see the impacts on user motivation, engagement and collaboration to 
encourage the business organization to replace the current development process with the proposed methodology.

The results that we obtained from our primary studies on applying game elements into software business landscapes shows that this issue still needs to work on it. It needs some empirical studies and also explicit evidences to adopt the gamification process into their development environment to make the whole process better. At the beginning of this literature review we expected that using gamification in software development process might resolve the problems related to human factors (e.g. user motivation, engagement and collaboration, etc.). Thus, the results that we obtained from our primary studies show that using game element in this area supports our expectations. Also it proves that using gamification into software development increases the user motivation, engagement and collaboration. It also proves that it increases the software quality and performance and resolves the obstacles related to human factors $[5,23,24]$. However, most of studies that we analyzed show that there are some gaps in the areas which are project management and configuration. In these primary studies of real life examples, the adoption of gamification process into software development process in the area project management and configuration perspective needs some real life examples and empirical work and evidence on it. Thus, it shows that it cannot be appropriately adopted into software development from the project management perspective.

Moreover, from the analyzed results, we realized that applying game elements into other business domains such as marketing, education [A7] is going faster than the software development process. However, in our opinion, it shows us that, the if the number of proposals, empirical studies and evidences increases for the adoption of gamification into software development to make the whole process better it may replace with current ecosystem of software development process successfully. Moreover, this process may be used extensively and preferred to use in the software development process in the software business landscapes doubtlessly.

\section{Appendix A}

[A1] K. Januszevski. (2012, Visual Studio Achievements ProgramsBrings Gamification to Development.

[A2] A. Dorling, McCaffery, F., "The gamification of SPICE,' Communications in Computer and Information Science, vol. 290, pp. 295-301, 2012.

[A3] J. Fernandes, D. Duarte, C. Ribeiro, C. Farinha, J. Madeiras Pereira, and M. Mira da Silva, "iThink: A Game-Based Approach Toward Improving Collaboration and Participation in Requirement Elicitation,' Procedia Computer Science, vol. 15, pp. 66-77, 20122012.

[A4] D. Duarte, C. Farinha, M. M. da Silva, and A. R. da Silva, "Collaborative Requirements Elicitation with Visualization Techniques,', presented at the Proceedings of the IEEE 21st International Workshop on Enabling Technologies: Infrastructure for Collaborative Enterprises (WETICE'12), 2012. 
[A5] R. Troughton, "Gamification in Software Development and Agile," Software Developer's Journal, 2012.

[A6] L. Singer and K. Schneider, "It was a bit of a race: Gamification of version control," in Proceedings of the $2^{\text {nd }}$ International Workshop on Games and Software Engineering (GAS'12), 2012, pp. 5-8.

[A7] S. K. Sheth, J. S. Bell, and G. E. Kaiser, "Increasing Student Engagement in Software Engineering with Gamification,'CUCS-018-12, Technical Report, Columbia University, Department of Computer Science, 2012.

[A8] S. Grant and B. Betts, "Encouraging user behavior with achievements: an empirical study," in Proceedings of the 10th Working Conference on Mining Software Repositories (MSR'13), 2013, pp. 65-68.

[A9] D. J. Dubois and G. Tamburrelli, "Understanding gamification mechanisms for software development," in Proceedings of the 9th Joint Meeting on Foundations of Software Engineering (ESEC/FSE'13), 2013, pp. 659-662.

[A10] A. A. de Melo, M. Hinz, G. Scheibel, C. D. M. Berkenbrock, I. Gasparini, and F. Baldo, "Version Control System Gamification: A Proposal to Encourage the Engagement of Developers to Collaborate in Software Projects,', presented at the Proceedings of the 6th Int. Conf. on Social Computing and Social Media (SCSM'2014).

\section{References}

1. M. Yilmaz, "A Software Process Engineering Approach to Understanding Software Productivity and Team Personality Characteristics: An Empirical Investigation", (January 2013)

2. K. Petersen, R. Feldt, S. Mujtaba, M. Mattsson, Systematic mapping studies in software engineering, in: Proceedings of the 12th International Conference on Evaluation and Assessment in Software Engineering (EASE'12), 2008, pp. 68-77

3. B. Kitchenham, "Procedures for Performing Systematic Reviews", Joint Technical Report Software Engineering Group, Department of Computer Science Keele University, United King and Empirical Software Engineering, National ICT Australia Ltd, Australia, 2004

4. S. Deterding and R. Khaled. Gamification: Toward a Definition. In CHI '11 Gamification Workshop. ACM, 2011.

5. S. Deterding, D. Dixon, R. Khaled, L. Nacke, From game design elements to gamefulness: defining gamification', in: Proceedings of the 15th International Academic MindTrek Conference, Envisioning Future Media Environments (MindTrek'11), 2011, pp. 9-15

6. B. Kitchenham and S. Charters, "Guidelines for performing systematic literature reviews in software engineering," Software Engineering Group, Keele University and Department of Computer Science, University of Durham, United Kingdom, Technical Report EBSE-2007$01,2007$.

7. K.M. Kapp, The Gamification of Learning and Instruction, Pfeiffer, 2012.

8. J. Currier, Gamification: Game Mechanics is the New Marketing, OogaLabs Blog, 2008.

9. StackOverflow. http://stackoverflow.com.

10. M. Hugos, Enterprise Games: Using Game Mechanics to Build a Better Business, O'Reilly, 2012

11. Atlassian, JIRA Hero. . 12. RedCritter, RedCritter Tracker. . 13. PropsToYou, "Props To You', ed. 14. ScrumKnowsy, "ScrumKnowsy", ed. 15. MasterBranch. .

16. M.V. Studio, Visual Studio Achievements, 2014 (July 2014). 
17. B.A. Kitchenham, D. Budgen, O. Pearl Brereton, Using mapping studies as the basis for further research - a participant-observer case study, Inf. Softw. Technol. 53 (2011) 638-651 $(06 / 01 / 2011)$.

18. J. C. de Almeida Biolchini, P. G. Mian, A. C. C. Natali, T. U. Conte, and G. H. Travassos, "Scientific research ontology to support systematic review in software engineering," Advanced Engineering Informatics, vol. 21, no. 2, pp. 133-151, Apr. 2007.

19. P. Brereton, B. Kitchenham, D. Budgen, M. Turner, M. Khalil, Lessons from applying the systematic literature review process within the software engineering domain, J. Syst. Softw. (2007) 571-583

20. T. Tsumaki and T. Tamai, "Framework for matching requirements elicitation techniques to project characteristics," Softw. Process Improv. Pract., vol. 11, no. 5, pp. 505-519, 2006

21. M. Herger, Enterprise Gamification: Engaging people by letting them have fun (Volume 1), 1st ed. CreateSpace Independent Publishing Platform, 2014

22. J. Hamari, J. Koivisto, and H. Sarsa, "Does Gamification Work? A Literature Review of Empirical Studies on Gamification," in System Sciences (HICSS), 2014 47th Hawaii International Conference on, 2014, pp. 3025-3034.

23. R. Paharia, Loyalty 3.0: How to Revolutionize Customer and Employee Engagement with Big Data and Gamification, McGraw-Hill, 2013.

24. K. Werbach, D. Hunter, For the Win: How Game Thinking Can Revolutionize Your Business, Wharton Digital Press, 2012. 